ORIGINAL ARTICLE

\title{
Extensive scanning of the calpain-3 gene broadens the spectrum of LGMD2A phenotypes
}

\section{G Piluso*, L Politano*, S Aurino, M Fanin, E Ricci, V M Ventriglia, A Belsito, A Totaro, V Saccone, H Topaloglu, A C Nascimbeni, L Fulizio, A Broccolini, N Canki-Klain, L I Comi, G Nigro, C Angelini, V Nigro}

See end of article for authors' affiliations Correspondence to Professor Vincenzo Nigro, Dipartimento di Patologia Generale, Facoltà di Medicina e Chirurgia, Seconda Università degli Studi di Napoli, Via Luigi De Crecchio 7, 80138 Naples, Italy; vincenzo. nigro@unina2.it

Revised version received 15 December 2004 Accepted for publication 23 December 2004

\begin{abstract}
Background: The limb girdle muscular dystrophies (LGMD) are a heterogeneous group of Mendelian disorders highlighted by weakness of the pelvic and shoulder girdle muscles. Seventeen autosomal loci have been so far identified and genetic tests are mandatory to distinguish among the forms. Mutations at the calpain 3 locus (CAPN3) cause LGMD type 2A.

Objective: To obtain unbiased information on the consequences of CAPN3 mutations.

Patients: 530 subjects with different grades of symptoms and 300 controls.

Methods: High throughput denaturing HPLC analysis of DNA pools.

Results: 141 LGMD2A cases were identified, carrying 82 different CAPN3 mutations (45 novel), along with 18 novel polymorphisms/variants. Females had a more favourable course than males. In $94 \%$ of the more severely affected patient group, the defect was also discovered in the second allele. This proves the sensitivity of the approach. CAPN3 mutations were found in $35.1 \%$ of classical LGMD phenotypes. Mutations were also found in $18.4 \%$ of atypical patients and in $12.6 \%$ of subjects with high serum creatine kinase levels.

Conclusions: A non-invasive and cost-effective strategy, based on the high throughput denaturing HPLC analysis of DNA pools, was used to obtain unbiased information on the consequences of CAPN3 mutations in the largest genetic study ever undertaken. This broadens the spectrum of LGMD2A phenotypes and sets the carrier frequency at 1:103.
\end{abstract}

imb girdle muscular dystrophies (LGMD) include a broad group of genetically determined progressive disorders -with a primary or predominantly symmetrical atrophy of the pelvic and/or shoulder girdle musculature, raised serum creatine kinase, and a necrotic regeneration pattern. ${ }^{1}$ The clinical course is characterised by great variability, ranging from severe forms with onset in the first decade and rapid progression, to milder forms with later onset and a slower course. The most severe forms result in dramatic physical weakness which often leads to other serious complications and, for many, a shortened life span. Other forms can result in relatively minor physical disabilities or develop late in life, allowing affected people to have normal life expectancy and activity levels.

Seventeen LGMD loci have so far been mapped, seven autosomal dominant and 10 autosomal recessive. ${ }^{2}$ The autosomal dominant forms (LGMDI) are generally milder and relatively rare, representing less than 10\% of all LGMD cases. $^{3-8}$ The autosomal recessive forms (LGMD2) are much more common, having a prevalence of 1:15 000, with geographical differences. ${ }^{9}$ The products of 10 LGMD2 loci have been identified. They are: calpain 3 for LGMD2A, ${ }^{10}$ dysferlin for LGMD2B, ${ }^{11}{ }^{12} \alpha$-sarcoglycan (adhalin) for LGMD2D, ${ }^{13} \beta$-sarcoglycan for LGMD2E, ${ }^{14}{ }^{15} \gamma$-sarcoglycan for LGMD2C, ${ }^{16} \delta$-sarcoglycan for $\mathrm{LGMD}_{2} \mathrm{~F}^{17}{ }^{18}$ telethonin for $\mathrm{LGMD}_{2 \mathrm{G}}{ }^{19}{ }^{19}$ TRIM32 for $\mathrm{LGMD}_{2} \mathrm{H},{ }^{20}$ fukutin related protein for LGMD2I, $^{21}$ and titin for LGMD2J. ${ }^{22}$ Linkage analyses indicate that there is further genetic heterogeneity for both LGMD1 and LGMD2.

LGMD2A [MIM 253600] is one of the most prevalent forms of autosomal recessive muscular dystrophy in all countries so far investigated and is caused by loss of function mutations in the CAPN3 gene. This spans $52.8 \mathrm{~kb}$ of genomic sequence at chromosome 15q15.1, and the $3.5 \mathrm{~kb}$ transcript is composed of 24 exons encoding a $94 \mathrm{kDa}$ proteolytic enzyme, calpain 3 or $\mathrm{p} 94 .{ }^{10}$ This is a skeletal muscle specific member of the superfamily of the calpain large subunits, or calcium activated neutral proteases (EC 3.4.22.17), which are nonlysosomal intracellular cysteine proteases. The human genome encodes at least 15 large subunit genes that are supposed to process various intracellular kinases, phosphatases, phospholipases, transcription factors, and cytoskeletal proteins to modulate their activities. ${ }^{23}$ Calpain 3 can be subdivided into four domains. Domain II shows similarity with other cysteine proteases, which share histidine, cysteine, and asparagine residues at their active sites. Domain IV comprises four EF-hand structures that are potential calcium binding sites. In addition, there are three unique sequences, NS, IS1, and IS2. Although it is largely unknown why the absence of this protein leads to muscular dystrophy, it has been suggested that it may play a significant role in intracellular signal transduction systems. ${ }^{24}{ }^{25}$ Baghdiguian et $a^{26}$ claimed that calpain 3 deficiency would cause myonuclear apoptosis and a profound perturbation of the IkBa/NF-kB pathway.

Null mutation of calpain 3 in mice causes abnormal sarcomere formation ${ }^{27}$ : in vitro studies showed that calpain 3 can bind and cleave titin and that some mutations result in reduced affinity for titin. The spectrum of mutations affecting the CAPN3 gene is highly heterogeneous. The Leiden muscular dystrophy web site (http://www.dmd.nl), a specialised mutation database for muscular dystrophies, to date

Abbreviations: CK, creatine kinase; HT-DHPLC, high throughput denaturing high performance liquid chromatography; LGMD, limb girdle muscular dystrophy 
reports 139 pathogenic mutations associated with a LGMD2A phenotype. They are distributed over almost all exons of the CAPN3 gene, with nine exons $(1,4,5,7,10,11,13,21$, and 22 ) involved in about $85 \%$ of cases. Most mutations (70\%) are private variants, although particular mutations were more frequent in some populations. Novel mutations were identified in Japanese LGMD2A patients, which were not found in non-Japanese populations. ${ }^{28}$

In a large study based on western blot analysis, 53 of 191 patients $(28 \%)$ with the LGMD phenotype had partial or total calpain 3 deficiency, while this was observed in $8 \%$ patients with hyperCKaemia, 6\% with proximal myopathy, and 6\% with distal myopathy. ${ }^{25}$ Recently, Fanin et al ${ }^{29}$ identified 69 of 208 cases of calpain 3 deficiency $(33.2 \%)$ by western blot analysis.

The present study was designed with two goals in mind: first, to approach the genetic heterogeneity of a complex disorder such as autosomal recessive LGMD with a noninvasive cost-effective strategy based on the screening of DNA pools; and second, to obtain a comprehensive nonbiased understanding of the consequences of CAPN3 mutations in myopathic patients, including isolated cases with different degrees of disease.

\section{METHODS}

\section{Selection of patients}

DNA samples from 530 LGMD patients and 300 controls were analysed by high throughput denaturing high performance liquid chromatography (HT-DHPLC) in the current survey. Patients in whom a mutation was afterwards identified in other LGMD genes were included. At least $92 \%$ of DNA samples were from Italian families, recruited at the Universities of Naples, Padua, and Rome. Additional patients were from Argentina (3), Croatia (6), Slovenia (5), Germany (6), Greece (1), and Turkey (20). Diagnostic criteria follow the European Neuromuscular Centre guidelines at http:// www.enmc.org/nmd/diagnostic.cfm. These include limb girdle onset, progression, autosomal inheritance, no involvement of other systems, raised serum creatine kinase (CK), hypodensity on computed tomographic scanning, dystrophic changes on muscle biopsy and so on. As a spectrum of disease severity has been observed in association with most of the genetically defined types, the exclusion of other disorders is a vital part of the general diagnosis of LGMD. Although there is a continuous spectrum of disease severity, we have grouped subjects into five categories: (A) severe LGMD characterised by serious weakness and wheelchair requirement before the age of 35; (B) intermediate LGMD with weakness and difficulty in deambulation, but the ability to walk alone beyond the age of 35; (C) mild with symmetrical scapular winging and hyperCKaemia; (D) isolated hyperCKaemia; and (P) presymptomatic, including patients too young to be classified by clinical criteria but with suggestive laboratory findings (for example, raised CK, myopathic biopsy, and so on).

In all, 123 were classified as group A, 142 as B, 158 as C, 87 as $\mathrm{D}$, and 20 as P. We included all isolated cases with apparent autosomal recessive inheritance. A preliminary linkage analysis using genetic markers specific for all the previously known limb girdle dystrophy loci was carried out on suitable families. ${ }^{30}$

\section{Mutation discovery strategy}

We used the following strategy (fig 1), structured into six sequential steps:

- Accurate quantification of genomic DNA, with a fluorometric assay using a reporter dye such as PicoGreen (Molecular Probes, Eugene, Oregon, USA).

- Dilution of each individual sample of genomic DNA and test of polymerase chain reaction (PCR) yield.

- Pooling of two suitable DNA samples in the same tube.

- Set up of finest PCR conditions, according to DHPLC analysis requirements (that is, special buffer formulations, primer design to mask known polymorphisms and so on).

- Mutation screening of the entire cohort of our patients and normal controls.

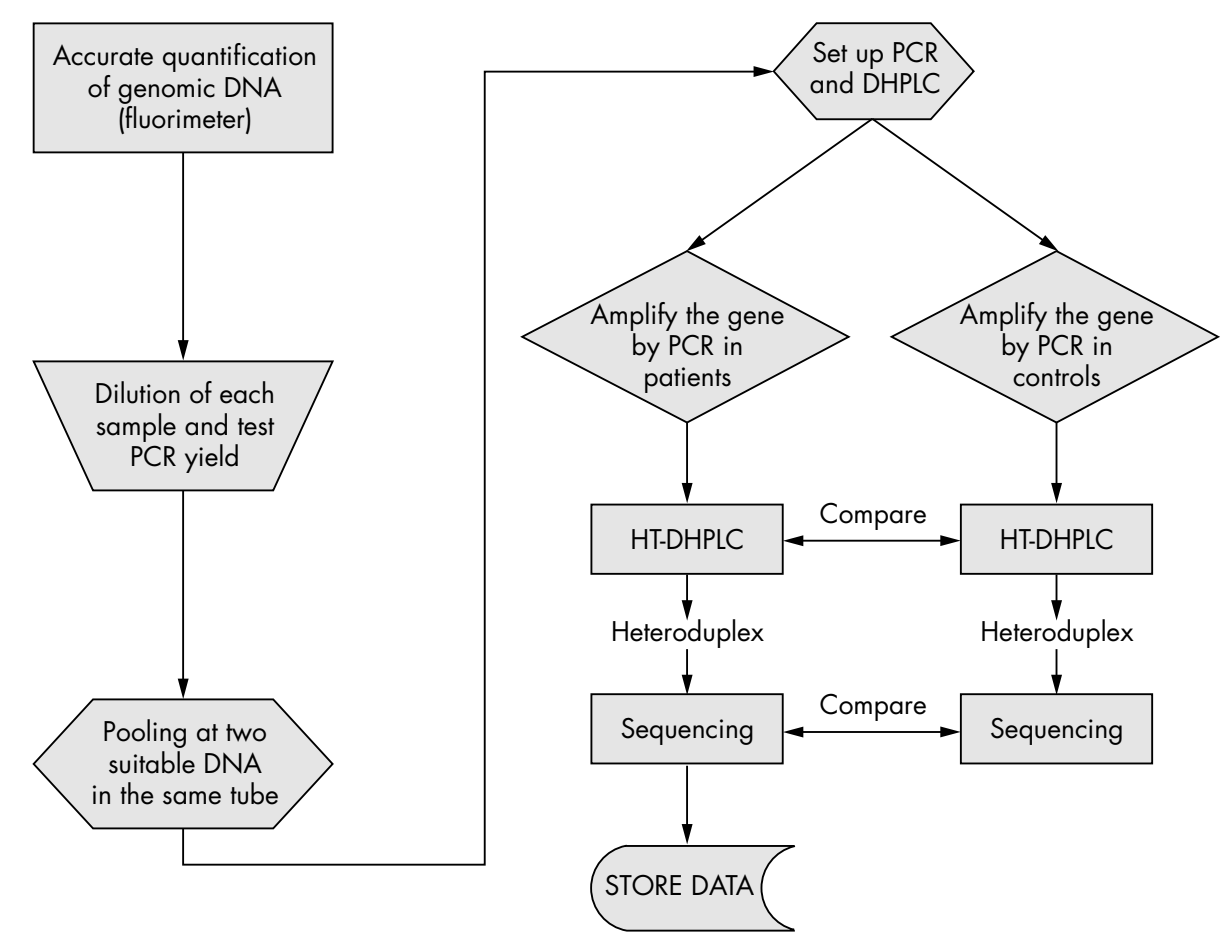

Figure 1 Flow chart showing the general design of the strategy. 
- Direct sequencing of abnormal migrating fragments only present in patients.

PCR primers for amplification of CAPN3 coding regions have been published previously. ${ }^{10}$ However, some of them produced amplicons showing suboptimal melting profiles when tested by Navigator software (Transgenomic Inc, Santa Clara, California, USA). In addition, the PCR yield was often unsuitable for the analysis. Thus most amplimers were redesigned. Table 1 reports the 26 PCR primer pairs for mutation screening of the coding sequence, together with the untranslated regions and the putative promoter. Amplified fragments were 93-296 bp in length. Here each primer pair was able to amplify an exon together with $25-50 \mathrm{bp}$ of flanking intron sequences on both sides. The mutation studies were undertaken using a combined procedure based on DHPLC and the assembly of normalised DNA pools to speed up the screening. The melting characteristics of each PCR fragment were predicted using Navigator software. The elution was carried out with a two minute gradient (Rapid DNA) with a flow of $1.5 \mathrm{ml} / \mathrm{min}$, a slope of $5 \% / \mathrm{min}$, and a drop loading of $3 \%$.

\section{RESULTS}

\section{DHPLC strategy and pooling rationale}

We analysed the CAPN3 exons and flanking intronic sequences and the putative promoter using high throughput denaturing HPLC (HT-DHPLC). ${ }^{31-36}$ The high throughput configuration of the instrument requires only a two minute gradient run for the analysis. Table 1 shows the sequence of the primers, PCR product sizes, annealing temperatures, and the conditions of analysis by DHPLC.

DHPLC can detect heterozygous mutations in DNA samples in the form of an additional peak of heteroduplex DNA. When a subject carries a homozygous mutation, it is necessary to anneal the sample with a normal control. Instead of normal samples, we pooled equal amounts of DNA from two unrelated patients before PCR. This was sufficient to reduce the number of DHPLC analyses and PCR reactions by at least $66 \%$. In fact, in both cases of a heterozygous or a homozygous mutation, heteroduplex DNA will be generated within a pool. A false negative on DHPLC can only result when a pool is composed of both DNAs that are homozygous for the same mutation. Nevertheless, this risk is very low, considering the frequency of the homozygous patients. Among the most frequent homozygous mutations were the following: 550delA was found in 12 of the 530 samples, 883886GATA $\rightarrow$ CTT and $2212 \mathrm{C} \rightarrow \mathrm{T}$ in four, 139delATC and $2242 \mathrm{C} \rightarrow \mathrm{T}$ in three, $802-9 \mathrm{G} \rightarrow \mathrm{A}$ and $2184 \mathrm{G} \rightarrow \mathrm{A}$ in two, and other 12 mutations only in one. Thus the probability of forming a false negative pool is $1: 1312\left(\mathrm{a}^{2}+\mathrm{b}^{2}+\mathrm{c}^{2}+\ldots / \mathrm{n}^{2}\right.$, where $n$ is the total number of samples; $214 / 280$ 900): too low to affect our analysis of 265 pools.

\section{Patients under study}

We studied a randomly collected group of 530 patients and 300 controls. Most patients are isolated cases with apparent autosomal recessive inheritance. We found at least one mutation in 141 patients and only 42 of these were homozygous (29.8\%). Eighty seven of them (61.7\%) were isolated cases, while 54 (38.3\%) were familial.

They were classified as severe LGMD (group A), intermediate LGMD (group B), mild myopathy (group C), asymptomatic hyperCKaemia (group D), and presymptomatic patients (group P). We found 49/123 mutations $(39.8 \%)$ in group A, 44/142 $(31.0 \%)$ in group B, 29/158 $(18.4 \%)$ in group C, $11 / 87(12.6 \%)$ in group $D$, and $8 / 20$ in group $\mathrm{P}(40.0 \%)$ (table 2 ). This strongly suggests that in typical LGMD with wheelchair confinement before or after age 35 (groups A and B), CAPN3 mutations are the most frequent genetic cause, as no other LGMD form involved $35.1 \%$ of patients. In addition, a mutation of the second allele was identified in the large majority of group A and B patients $(46 / 49=93.9 \%$ and $38 / 44=86.4 \%$, respectively $)$, but only in $15 / 29=51.7 \%$ of group $\mathrm{C}$ and $3 / 11=27.3 \%$ of group D

Table 1 Primers, polymerase chain reaction (PCR) product sizes, annealing temperatures, and high throughput denaturing high performance liquid chromatography (HT-DHPLC) analysis conditions for all the exons of the CAPN3 gene

\begin{tabular}{|c|c|c|c|c|c|}
\hline \multirow[b]{2}{*}{ Exon } & \multicolumn{2}{|l|}{ Primers $5^{\prime}-3^{\prime}$} & \multirow{2}{*}{$\begin{array}{l}\text { Product size } \\
\text { (bp) }\end{array}$} & \multirow{2}{*}{$\begin{array}{l}\text { PCR } \\
\text { temperature } \\
\left({ }^{\circ} \mathrm{C}\right)\end{array}$} & \multirow{2}{*}{$\begin{array}{l}\text { DHPLC } \\
\text { temperature } \\
\text { ( } \mathrm{C} \text { ) }\end{array}$} \\
\hline & Forward & Reverse & & & \\
\hline Prom & Ttcagtacctcccgitcacc & gatgcttgagccaggaaaac & 296 & 60 & 58.5 \\
\hline $1 \mathrm{~A}$ & Ctttccttgaaggtagctgtat & cggctgatgatggctgaatagatgc & 210 & 60 & 64.5 \\
\hline $1 B$ & gaggctgggggtggaaacccaagtg & gaggtgctgagtgagaggac & 279 & 60 & 59 \\
\hline 2 & Actccgtctcaaaaaaatacct & attgtecctttacctcctgg & 239 & 60 & 58.5 \\
\hline 3 & Ctcacgatctgtgccctgtgtc & cgctggecctcttaactacactctc & 185 & 60 & 61.4 \\
\hline 4 & ggacacatttcctaacagtaatttgagt & ctagecccacctcacattctaaag & 227 & 60 & 61.7 \\
\hline 5 & Gtgaccccaaattggtcttcat & ggtaaaaggcttcctgacacttg & 262 & 60 & 60.7 \\
\hline 6 & ccctgtg ttgittccctacattct & ggagggatggtcagttctgata & 220 & 58 & 59.5 \\
\hline 7 & aatgggttctctggitactgc & cttcatgaggttaacccaggag & 169 & 60 & 63 \\
\hline 8 & acagaagattccctttccagaga & atcttcaatactctcatgg ctcagt & 239 & 60 & 63.5 \\
\hline 9 & cctgcttccttaattcctccatttt & ctcttccecaccettacccttct & 159 & 60 & 60.3 \\
\hline 10 & cctcctcacctgctcccata & Htttcggcttagaccctcc & 252 & 60 & 64 \\
\hline 11 & gtgaatgcgtgcttccttctg & aaagtatgtttcctgggctggag & 242 & 60 & 62.7 \\
\hline 12 & attcacatctgaagcatcttcctt & gtagtgctgcacacaactgctg & 93 & 60 & 56.3 \\
\hline 13 & tgtggcaggacaggacgttc & Hcaacctctggagtgggec & 337 & 60 & 63 \\
\hline 14 & gggttctctagaggctggittct & gacttttcgcacagaagatctaaac & 191 & 60 & 62 \\
\hline 15 & tcacttattctgcatttactgittcc & agtacacacacttcatgctctctacc & 94 & 60 & 52.4 \\
\hline 16 & cagactgtaatcctccettccttcctg & tgtagcgtgctggccaccccac & 205 & 60 & 62.1 \\
\hline 17 & acctctgacccctgtgaacc & gcgtcctgggcttggaggtac & 146 & 58 & 60 \\
\hline 18 & tcctgaaccatgaccctcctct & ctgctttgagacaacgggactc & 154 & 60 & 60 \\
\hline 19 & tcctcactcttctccatccc & accctgtatgttgccttgg & 159 & 60 & 62.5 \\
\hline 20 & gtgtgctgtgtagccctgacctc & cttgactcccacgcttcattttct & 134 & 60 & 60.3 \\
\hline 21 & gaatggggttgatttggagattcag & cacatccctgecaccecttc & 170 & 60 & 61.4 \\
\hline 22 & ctccacgtccacctctaacatgg & agaggg ageccccctctccca & 179 & 60 & 61.4 \\
\hline 23 & tctggcctgtgcattctttcac & ccctccaccttgagtttlaatg & 137 & 60 & 58.5 \\
\hline 24 & gggtcactcttttctgatctaca & agggtgaaactgaaatcctgag & 131 & 60 & 60 \\
\hline
\end{tabular}


patients. As the sensitivity of DHPLC is identical for all samples, a large proportion of heterozygous patients belonging to group $\mathrm{C}$ and D might not have a second mutation. In milder myopathies CAPN3 mutations are no more common than DYSF or FKRP mutations. The mutation detection rate among patients with defects of calpain 3 on western blot analysis was $56 \%$.

The CK level in patients in all groups was 11.1-fold above the upper limit of normal (range threefold to 25-fold). However, there were some young patients who had very high CK levels (up to $100 \times$ ) and four with normal CK.

In accordance with the observations of Zatz and coworkers, ${ }^{37}$ we found more rapid progression in LGMD2A affected males than in females. Considering patients with both mutations, females in $34.0 \%$ of cases were in group A, $48.9 \%$ were in group B, while in the males $52.6 \%$ were in group A and $26.3 \%$ in group B. As the difference between groups $\mathrm{A}$ and $\mathrm{B}$ depends on the age of wheelchair confinement, females tend to lose their ability to walk later.

\section{Mutations and polymorphisms}

Altogether, 82 different mutated alleles were detected in the CAPN3 gene, of which $45(54.9 \%$ ) are novel (table 3$)$. No putative mutations were encountered in 300 controls. The mutations include 66 single base pair substitutions (18 transversions and 48 transitions) which resulted in a change of amino acid in 54 cases $(81.8 \%)$, in premature stop codons in five cases, and in splicing defects in seven cases. An additional 11 mutations were small deletions, one was an insertion, and two were indels. All but five caused a frame shift, leading to a secondary premature stop codon. We identified 27 novel mutations affecting single amino acids that are conserved. However, this criterion is not fully reliable as the conserved glutamic acid 107 is polymorphic in humans. Some mutations affect domains that are common to all the other members of the calpain superfamily: for example, F779 is part of an EF-hand calcium binding motif DFXXF. Patients with the same mutations have a variable phenotypic spectrum. For example, among 12 cases that are homozygous for the 550delA allele, six belong to group A, five to group B, and one to group C.

When the mutation of the second allele was not found, we tried to identify it by reverse transcriptase polymerase chain reaction (RT-PCR) from muscle RNA, when available. We also carried out long range PCR analysis. No major genomic deletion in the calpain 3 gene was identified among these patients.

We found mutations scattered over 21 of the 24 exons of the CAPN3 gene, with no mutation in exons 9 (78 bp), 12 (12 bp), and 23 (59 bp), all of which are among the smallest exons and in which no definite mutation has been described so far. Interestingly, we found 10 mutations in exon 1, seven of which are novel (70\%). Alternatively spliced exons, such as 15 and 16, relatively more often show out of frame mutations.

We identified three novel polymorphisms $(498+35 \mathrm{G} \rightarrow \mathrm{T}$, $606 \mathrm{~T} \rightarrow \mathrm{C}$, and $1524+81 \mathrm{C} \rightarrow \mathrm{T}$ ) found both in patients and controls, and 15 novel variants in addition to others that are already known (table 4). This could be a major drawback for the analysis, as polymorphisms generate heteroduplexes that may mask true mutations. We therefore designed additional primers that cover these polymorphisms and rescreened samples. We only sequenced the heteroduplexes that were maintained following this second PCR. Otherwise, we have sequenced all the heteroduplex-forming fragments to avoid missing mutations. We were unable to show an association between six synonymous and non-synonymous variants and LGMD2A: these were found only once in patients and not in controls and therefore could not be classified (table 4).

\section{DISCUSSION}

We present the results of all the sequence variations identified in the CAPN3 gene. Mutations of the CAPN3 gene cause the most prevalent form of limb girdle muscular dystrophy, LGMD2A. The phenotypic consequences of CAPN3 defects are similar to those caused by mutations in many other known and unknown LGMD genes. This immediately indicates first, that direct genetic testing is necessary to discriminate between the forms; and second, that in a large fraction of LGMDs a CAPN3 mutation can be found. Unfortunately, the analysis of CAPN3 gene is complex, as it is composed of 24 exons and has 218 pathogenic and nonpathogenic alleles, including those reported here. There is also no prevalent "hot spot" mutation that can be routinely screened, unlike the cystic fibrosis gene.

We set up a high throughput strategy for the systematic analysis of the CAPN3 gene using DHPLC. All comparative

Table 2 Distribution of the mutations by sex and group

\begin{tabular}{|c|c|c|c|c|c|c|c|}
\hline & & Group A & Group B & Group C & Group D & Group P & Total \\
\hline \multirow[t]{5}{*}{ Male } & $\mathrm{HO}^{*}$ & 11 & 6 & 3 & 0 & 1 & 21 \\
\hline & $\mathrm{CHE} \dagger$ & 19 & 9 & 5 & 3 & 0 & 36 \\
\hline & HE & 3 & 2 & 12 & 7 & 3 & 27 \\
\hline & Total mutated & 33 & 17 & 20 & 10 & 4 & 84 \\
\hline & Total studied & 81 & 64 & 138 & 71 & 10 & 364 \\
\hline \multirow[t]{5}{*}{ Female } & $\mathrm{HO}^{*}$ & 9 & 9 & 3 & 0 & 0 & 21 \\
\hline & $\mathrm{CHE} †$ & 7 & 14 & 4 & 0 & 1 & 26 \\
\hline & HE‡ & 0 & 4 & 2 & 1 & 2 & 9 \\
\hline & Total mutated & 16 & 27 & 9 & 1 & 3 & 57 \\
\hline & Total studied & 42 & 78 & 20 & 16 & 10 & 166 \\
\hline \multirow[t]{5}{*}{ Total } & $\mathrm{HO}^{*}$ & 20 & 15 & 6 & 0 & 1 & 42 \\
\hline & CHE† & 26 & 23 & 9 & 3 & 1 & 62 \\
\hline & HE‡ & 3 & 6 & 14 & 8 & 6 & 37 \\
\hline & Total mutated & 49 & 44 & 29 & 11 & 8 & 141 \\
\hline & Total studied & 123 & 142 & 158 & 87 & 20 & 530 \\
\hline \multicolumn{8}{|c|}{$\begin{array}{l}\text { *Homozygous; †compound heterozygous; theterozygous. } \\
\text { Groups: (A) severe limb girdle muscular dystrophy (LGMD) characterised by serious weakness and wheelchair } \\
\text { requirement before the age of } 35 ;(B) \text { intermediate LGMD with weakness and difficulty in deambulation, but the } \\
\text { ability to walk alone beyond the age of } 35 ;(C) \text { mild with symmetrical scapular winging and hyperCKaemia; (D) } \\
\text { isolated hyperCKaemia; and (P) presymptomatic, including patients too young to be classified by clinical criteria } \\
\text { but with suggestive laboratory findings. }\end{array}$} \\
\hline
\end{tabular}


Table 3 Causative mutations identified in the CAPN3 gene

\begin{tabular}{|c|c|c|c|c|c|c|}
\hline Exon & $\begin{array}{l}\text { Nucleotide change (cDNA, } \\
\text { NM_000070) }\end{array}$ & $\begin{array}{l}\text { Amino acid change (protein, } \\
\text { NP_000061) }\end{array}$ & $\mathrm{HE}^{*}$ & CHE† & HO¥ & HO families \\
\hline \multirow[t]{10}{*}{1} & $77 \mathrm{C} \rightarrow \mathrm{T}$ & P26L & 1 & - & - & \\
\hline & 139_141del & 147del & - & - & 3 & (2) \\
\hline & $143 \bar{G} \rightarrow A$ & $\mathrm{~S} 48 \mathrm{~N}$ & 1 & - & - & \\
\hline & $146 \mathrm{G} \rightarrow \mathrm{A}$ & $\mathrm{R} 49 \mathrm{H}$ & - & 2 & - & \\
\hline & $229 \mathrm{G} \rightarrow \mathrm{A}$ & D77N & 2 & 3 & - & \\
\hline & $245 \mathrm{C} \rightarrow \mathrm{T}$ & P82L & 2 & 2 & 1 & (1) \\
\hline & 247_251del & D83_E84delfs +2X5 & - & 2 & - & \\
\hline & $259 \mathrm{C} \rightarrow \mathrm{G}$ & L87V & 1 & - & - & \\
\hline & $304 \mathrm{C} \rightarrow \mathrm{T}$ & P102S & - & 1 & - & \\
\hline & $308 \mathrm{C} \rightarrow \mathrm{T}$ & P103L & 1 & 0 & 0 & \\
\hline \multirow[t]{2}{*}{2} & $319 \mathrm{G} \rightarrow \mathrm{A}$ & E107K & 1 & - & - & \\
\hline & $328 \mathrm{C} \rightarrow \mathrm{T}$ & R110X & 2 & 2 & - & \\
\hline \multirow[t]{3}{*}{3} & $398 \mathrm{C} \rightarrow \mathrm{T}$ & A133V & - & 2 & - & \\
\hline & $479 \mathrm{C} \rightarrow \mathrm{G}$ & Al60G & 1 & - & - & \\
\hline & $498+1 G \rightarrow A$ & Splicing & - & 1 & - & \\
\hline \multirow[t]{6}{*}{4} & $533 \mathrm{~T} \rightarrow \mathrm{C}$ & $1178 \mathrm{~T}$ & - & - & 1 & (1) \\
\hline & $548 \mathrm{C} \rightarrow \mathrm{G}$ & P183R & - & 1 & - & \\
\hline & 550 delA & T184fs+1X35 & 2 & 19 & 12 & (10) \\
\hline & $590 \mathrm{G} \rightarrow \mathrm{A}$ & R197H & - & 2 & - & \\
\hline & 598_612del & F200_L204del & 1 & 6 & - & \\
\hline & $620 \bar{A} \rightarrow C$ & K207T & - & 1 & - & \\
\hline \multirow[t]{12}{*}{5} & $633 \mathrm{G} \rightarrow \mathrm{T}$ & K211N & 1 & - & - & \\
\hline & $649 \mathrm{G} \rightarrow \mathrm{A}$ & E217K & - & 1 & - & \\
\hline & $664 \mathrm{G} \rightarrow \mathrm{A}$ & G222R & - & 1 & - & \\
\hline & $674 \mathrm{C} \rightarrow \mathrm{G}$ & $\mathrm{T} 225 \mathrm{R}$ & - & 1 & - & \\
\hline & $689 A \rightarrow G$ & D230G & - & - & 1 & (1) \\
\hline & $697 \mathrm{G} \rightarrow \mathrm{C}$ & G233R & - & 1 & - & \\
\hline & $701 \mathrm{G} \rightarrow \mathrm{A}$ & G234E & - & 1 & - & \\
\hline & $739 G \rightarrow A$ & D247N & 1 & - & - & \\
\hline & $755 \mathrm{~T} \rightarrow \mathrm{C}$ & M252T & 1 & - & - & \\
\hline & $755 \mathrm{~T} \rightarrow \mathrm{A}$ & M252K & - & 2 & - & \\
\hline & 759_761del & K254del & - & 1 & - & \\
\hline & $801+1 \mathrm{G} \rightarrow \mathrm{A}$ & Splicing & - & 2 & - & \\
\hline \multirow[t]{3}{*}{6} & $802-9 G \rightarrow A$ & Splicing & - & 6 & 2 & (1) \\
\hline & $848 \mathrm{~T} \rightarrow \mathrm{C}$ & M283T & - & - & 1 & (1) \\
\hline & 883_886delGATAinsCTT & D295delfs+1X55 & - & - & 4 & (1) \\
\hline 7 & $956 \mathrm{C} \rightarrow \mathrm{T}$ & P319L & - & 1 & - & \\
\hline & $964 \mathrm{~T} \rightarrow \mathrm{C}$ & Y322H & 1 & - & - & \\
\hline & $967 \mathrm{G} \rightarrow \mathrm{T}$ & E323X & - & 1 & 1 & (1) \\
\hline & $1000 \mathrm{C} \rightarrow \mathrm{T}$ & H334Y & - & 1 & - & \\
\hline & 1001_1002insA & H334fs-2X8 & - & - & 1 & (1) \\
\hline 8 & $1058 \overline{\mathrm{T}} \rightarrow \mathrm{C}$ & L353P & 1 & - & - & \\
\hline & $1061 T \rightarrow C$ & V354A & - & 1 & - & \\
\hline & $1061 \mathrm{~T} \rightarrow \mathrm{G}$ & V354G & - & 1 & - & \\
\hline 10 & $1291 \mathrm{G} \rightarrow \mathrm{A}$ & V431M & 1 & - & - & \\
\hline & $1303 G \rightarrow A$ & E435K & 1 & 1 & - & \\
\hline & $1309 \mathrm{C} \rightarrow \mathrm{T}$ & R437C & - & 2 & 1 & (1) \\
\hline & $1342 C \rightarrow T$ & R448C & 1 & - & 1 & (1) \\
\hline & $1343 G \rightarrow A$ & $\mathrm{R} 448 \mathrm{H}$ & - & 2 & - & \\
\hline 11 & 1401_1403del & E467del & 1 & 3 & - & \\
\hline & $1448 \mathrm{C} \rightarrow \mathrm{A}$ & A483D & - & 1 & - & \\
\hline & $1465 \mathrm{C} \rightarrow \mathrm{T}$ & R489W & - & 2 & - & \\
\hline & $1468 C \rightarrow T$ & R490W & - & $\overline{1}$ & - & \\
\hline & $1469 G \rightarrow A$ & R490Q & - & 1 & 1 & (1) \\
\hline & $1477 C \rightarrow G$ & R493G & - & 1 & - & \\
\hline 13 & $1611 \mathrm{C} \rightarrow \mathrm{A}$ & Y537X & - & 1 & - & \\
\hline & $1621 \mathrm{C} \rightarrow \mathrm{T}$ & R541W & - & 6 & 1 & (1) \\
\hline & $1622 \mathrm{G} \rightarrow \mathrm{A}$ & R541Q & - & 7 & - & \\
\hline & $1706 \mathrm{~T} \rightarrow \mathrm{C}$ & F569S & 1 & - & - & \\
\hline & $1714 \mathrm{C} \rightarrow \mathrm{T}$ & R572W & - & 1 & - & \\
\hline & $1715 G \rightarrow C$ & R572P & 1 & - & - & \\
\hline & $1745+1 G \rightarrow A$ & Splicing & - & - & 1 & (1) \\
\hline 14 & $1746-20 C \rightarrow G$ & Splicing & 2 & 3 & - & \\
\hline 15 & $1792 \_1795 \mathrm{del}$ & K598_T599delfs+1X62 & 1 & 3 & - & \\
\hline 16 & $1817 \mathrm{C} \rightarrow \mathrm{T}$ & S606L & - & 1 & - & \\
\hline & 1865 delAG & $\mathrm{E} 622 \mathrm{fs}_{\mathrm{s}}+2 \times 7$ & - & 2 & - & \\
\hline & 1868_1877del & E623_G626delfs+1X34 & - & 1 & - & \\
\hline 17 & 1917_1922del & Q640_P641del & 1 & - & - & \\
\hline & $1984 \mathrm{G} \rightarrow \mathrm{T}$ & A662S & 1 & - & - & \\
\hline & $1992+1 G \rightarrow T$ & Splicing & - & 3 & - & \\
\hline 18 & 2020_2022del & K674del & - & 1 & - & \\
\hline 19 & $2105 \mathrm{C} \rightarrow \mathrm{T}$ & A702V & 1 & - & 1 & (1) \\
\hline 20 & $2184 G \rightarrow A$ & Q728Q (splicing) & 1 & - & 2 & (1) \\
\hline 21 & 2204_2205del & $T 736 \mathrm{fs}+2 \times 27$ & - & 1 & - & \\
\hline & $2212 \mathrm{C} \rightarrow \mathrm{T}$ & Q738X & - & - & 4 & (1) \\
\hline & $2242 C \rightarrow T$ & R748X & 2 & 9 & 3 & (3) \\
\hline & $2243 G \rightarrow A$ & $\mathrm{R} 748 \mathrm{Q}$ & 1 & - & - & \\
\hline & 2257delGinsAA & D753fs-2X10 & - & 1 & - & \\
\hline & $2257 \mathrm{G} \rightarrow \mathrm{A}$ & D753N & 1 & 3 & - & \\
\hline
\end{tabular}


Table 3 Continued

\begin{tabular}{|c|c|c|c|c|c|c|}
\hline Exon & $\begin{array}{l}\text { Nucleotide change (cDNA, } \\
\text { NM_000070) }\end{array}$ & $\begin{array}{l}\text { Amino acid change (protein, } \\
\text { NP_000061) }\end{array}$ & $\mathrm{HE}^{*}$ & CHE† & HO¥ & HO families \\
\hline \multirow[t]{2}{*}{22} & $2330 \mathrm{~T} \rightarrow \mathrm{C}$ & I777T & - & 1 & - & \\
\hline & $2335 \mathrm{~T} \rightarrow \mathrm{A}$ & F779I & 1 & - & - & \\
\hline 24 & 2440-9_-6del & Splicing & - & 1 & - & \\
\hline
\end{tabular}

studies between methods for mutation discovery confirmed the greater efficacy of DHPLC, which offers the advantages of sensitivity, automation, and cost-effectiveness. ${ }^{31-36}$ In addition, HT-DHPLC adds a fourth benefit, speed. Compared with standard DHPLC, it cuts analysis time and reduces human intervention: two 384 well plates (768 samples) are automatically analysed in 54 hours. For further enhancement, we analysed PCR products from DNA pools, as the system is able to distinguish a mutant allele among several wild-type alleles. Sample pooling before PCR cuts the costs of the entire procedure, making it the cheapest of all the mutation discovery strategies. In comparison with direct sequencing, standard DHPLC is at least eight times cheaper, ${ }^{32}$ but together with high throughput sample pooling the entire procedure becomes up to 20 times cheaper.

With DHPLC, any sequence polymorphism that generates heteroduplex DNA may confound results by masking pathogenic changes. This problem can be solved in two different ways: first, by sequencing all the heteroduplex forming fragments to avoid missing mutations; second, by designing primers that cover or exclude the polymorphic site, when the latter is intronic. We show that our approach to mutation discovery had an optimal sensitivity based on the following data: in more than $90 \%$ of patients with typical severe or intermediate LGMD (groups A and B) we were able to discover the second allele mutation. DNA based exon analyses miss deep intronic mutations that activate cryptic splice sites by adding extra sequences. This does not seem to be the case, as RT-PCR, when possible, was unable to detect any defect.

A general problem of human molecular genetics is in the genotype-phenotype correlation for non-truncating mutations. Mutation discovery strategies should discriminate between true pathogenic defects versus rare innocuous variants. Even if the disease is familial and strongly linked to a locus, one must take into account that any sequence variation co-segregates with the true but unidentified mutation. Thus each variation observed only once should be considered a "putative mutation" only when a complete study of the gene and an adequate number of controls has been made. This implies that heterozygous status should not be classified as autosomal recessive LGMD2A in the absence of the second mutation. The number of controls is a critical issue and depends on the heterogeneity of neutral alleles. ${ }^{38}$ We consider the standard analysis of 100 normal individuals inadequate. Pooled DHPLC analysis can achieve this goal by increasing the number of chromosomes analysed at reasonable cost.

Unlike all the other studies on LGMD2A, we included isolated cases and milder and atypical patients. This is helpful in defining a wider non-biased phenotypic spectrum associated with defects at the CAPN3 locus.

We identified 82 different mutations. The distribution of mutations along the gene somewhat differs from that reported in the literature, suggesting both population differences and methodological bias. The most frequently

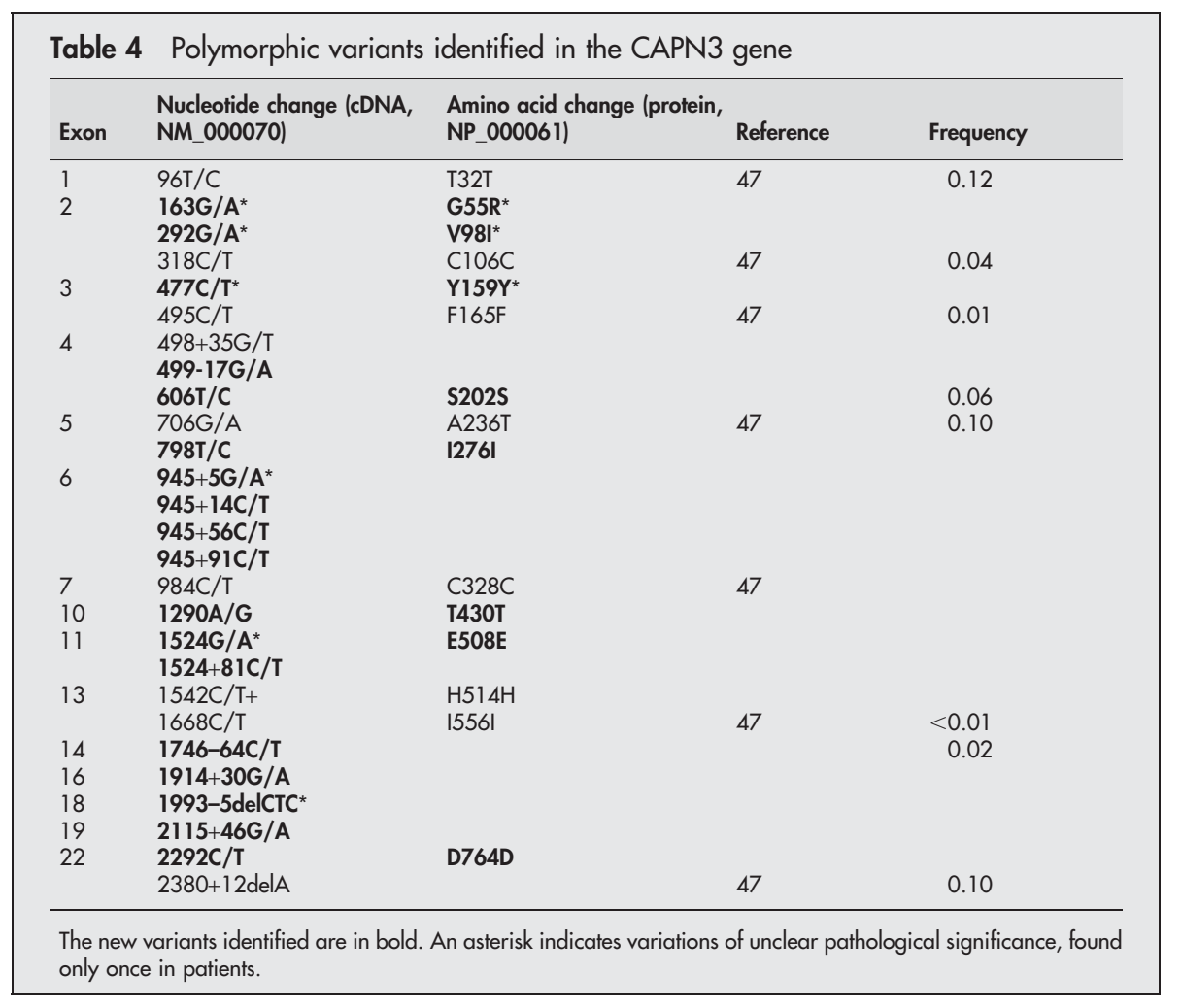


mutated exons in our study are 1, 4, 5, 6, 7, 10, 11, 13, and 21 accounting for $87 \%$ of all LGMD2A alleles. In Brazilian families, exons 2 and 22 should be included in the amplicons first analysed. Unexpectedly, we found 10 exon 1 variants that constitute $70 \%$ of all mutations described worldwide. This may be result from a fault in the screening of this exon by most groups, as our detection rate was enhanced when we split exon 1 in two overlapping fragments (table 1). The most frequent allele is del 550 A which was found 45 times. Six of 12 del550 homozygous patients were from north eastern Italy. The fraction is much lower than in Croatia, ${ }^{39}$ but higher than in southern Italy. This confirms the hypothesis of a common founder. ${ }^{40}$

We then compared mutation discovery results with available western blot data. Seventy patients with reduced or absent calpain 3 western blot were analysed and we found a causative mutation in $56 \%$ of cases. This, together with the data by Fanin et al, ${ }^{29}$ implies that western blot analysis alone could give both to false positive and false negative results. The conclusive diagnosis of LGMD2A is thus molecular. We show that reliability only derives from very large patient-tocontrol studies that are feasible using high throughput mutation analysis techniques.

Accordingly, the milder the phenotype, the higher the percentage of patients with one single CAPN3 mutation. Considering group A and B patients in the current definition of LGMD with autosomal recessive inheritance, 93 of 265 subjects $(35.1 \%)$ can be classified as LGMD2A. Mutations were also found in patients belonging to group C (18.4\%) in half of which the second mutation was not found. The results of the screening indicate that $12.6 \%$ of patients with no weakness and increased CK levels (group D) do have CAPN3 mutations.

At the end of this study there were patients from groups $C$ and D with a single pathogenic change. We think that these patients may either be true heterozygotes for a pathogenic CAPN3 allele or may carry a yet unrecognised hypomorphic allele variation. In some of these patients, we found polymorphisms or variants, also identified in normal controls: one should assume that they are neutral changes. However, the combination of a polymorphism in one copy of the CAPN3 gene with an LGMD2A mutation in the other copy could even be responsible for very mild phenotypes with low penetrance, similar to the effect of the 5T allele in cystic fibrosis. ${ }^{41} 42$

The more rapid progression in affected males than females has no explanation. If sex steroids modulate the calpain 3 mechanism, this could have implications for treatment.

When the involvement of CAPN3 gene in disease was reported for the first time, ${ }^{10}$ six different mutations were found within La Réunion Island patients, although a single founder was expected. A digenic inheritance model and several alternative hypotheses were proposed by Beckmann to explain the so called "La Réunion paradox." Considering the number of patients recruited by all centres and the population of origin, we estimate that autosomal recessive LGMDs have a cumulative prevalence of 1:15 000, and 35.1\% of the cases are LGMD2A. Thus the prevalence of typical LGMD2A should be 1:42 700 and the carrier frequency 1:103. Additional mutations are carried by atypical patients or subjects with high CK, most of which are not recruited for genetic studies. This recalculation of the carrier frequency helps to explain the paradox. La Reunion now has a population of 720900 people, so we expect to find at least 7000 disease carriers. During the years 1707 to 1804 the population of the island increased 88 -fold. This implies that multiple waves of immigration occurred and many different founders were introduced.
To our knowledge, this is the largest molecular study of LGMD2A in a highly heterogeneous population of patients. CAPN3 mutations account for about one third of classical LGMD cases and the other nine genes account for about an additional third of cases; the remaining third will be caused by as yet unknown genetic causes. The question arises as to whether there is a multitude of genes each accounting for a limited number of these cases, or there are a few major disease genes that cause all these forms. The former may be more realistic and similar to the widespread genetic heterogeneity observed in other human diseases (for example, retinitis pigmentosa or mental retardation). ${ }^{43-47}$

\section{DATA ACCESS}

We will make available materials used for the present investigation upon justified request to the corresponding author. Mutation information is being submitted to Leiden public database.

\section{ACKNOWLEDGEMENTS}

We thank all the LGMD families. We acknowledge Maria Esposito and Manuela Dionisi at the TIGEM Mutation Detection facility. We also thank Francesca D'Amico and Maria Rosaria Righetti for help in mutation discovery and the TIGEM-IGB sequencing core facility. Control samples were from Naples Human Mutation Gene Bank.

\section{Authors' affiliations}

G Piluso*, V M Ventriglia*, V Nigro, Dipartimento di Patologia Generale e Centro di Eccellenza per le malattie cardiovascolari, Seconda Università di Napoli, Naples, Italy

L Politano, L I Comi, G Nigro, Servizio di Cardiomiologia e Genetica Medica, Dipartimento di Medicina Sperimentale, Seconda Università di Napoli

S Aurina, A Belsito, A Totaro, V Saccone, Telethon Institute of Genetics and Medicine (TIGEM), Naples

M Fanin, C Angelini, Dipartimento di Neuroscienze, Università di Padova, Padova, Italy

A C Nascimbeni, L Fulizio, Venetian Institute of Molecular Medicine, Padova

E Ricci, A Broccolini, Dipartimento di Neuroscienze, Università Cattolica, Rome, Italy

H Topaloglu, Department of Child Neurology, Hacettepe Children's Hospital, Ankara University, Ankara, Turkey

N Canki-Klain, Croatian Institute for Brain Research, Zagreb University Medical School, Zagreb, Croatia

Competing interests: none declared

*Both authors contributed equally to this work

\section{REFERENCES}

1 Emery AE. The muscular dystrophies. Lancet 2002;359:687-95.

2 Zatz M, de Paula F, Starling A, Vainzof $M$. The 10 autosomal recessive limbgirdle muscular dystrophies. Neuromuscul Disord 2003;13:532-44.

3 Hauser MA, Horrigan SK, Salmikangas P, Vles KD, Tim RW, Torian UM, Taivainen U, Bartoloni L, Dancel R, Gilchrist JM, et al. Myotilin is mutated in limb girdle muscular dystrophy 1A. Hum Mol Genet 2000;9:2141-7.

4 Bonne G, Di Barletta MR, Varnous S, Becane HM, Hammouda EH, Merlini L, Muntoni F, Greenberg CR, Gary F, Urtizberea JA, Duboc D, Fardeau M, Toniolo D, Schwartz K. Mutations in the gene encoding lamin A/C cause autosomal dominant Emery-Dreifuss muscular dystrophy. Nat Genet 1999;21:285-8.

5 Minetti C, Sotgia F, Bruno C, Scartezzini P, Broda P, Bado M, Masetti E, Mazzocco P, Egeo A, Donati MA. Mutations in the caveolin-3 gene cause autosomal dominant limb-girdle muscular dystrophy. Nat Genet 1998; 18:365-8.

6 Speer MC, Vance JM, Grubber JM, Lennon-Graham F, Staiich JM, Viles KD, Rogala A, McMichael R, Chutkow J, Goldsmith C, Tim RW, Pericak-Vance MA. Identification of a new autosomal dominant limb-girdle muscular dystrophy locus on chromosome 7. Am J Hum Genet 1999:64:556-62.

7 Palenzuela L, Andreu AL, Gamez J, Vila MR, Kunimatsu T, Meseguer A, Cervera C, Fernandez Cadenas I, van der Ven PF, Nygaard TG, Bonilla E, Hirano M. A novel autosomal dominant limb-girdle muscular dystrophy (LGMD 1F) maps to 7q32.1-32.2. Neurology 2003;61:404-6.

8 Starling A, Kok F, Passos-Bueno MR, Vainzof M, Zatz M. A new form of autosomal dominant limb-girdle muscular dystrophy (LGMDIG) with progressive fingers and toes flexion limitation maps to chromosome 4p21. Eur J Hum Genet 2005;13:264. 
9 Nigro V. Molecular bases of autosomal recessive limb-girdle muscular dystrophies. Acta Myol 2003;22:35-42.

10 Richard I, Broux O, Allamand V, Fougerousse F, Chiannilkulchai N, Bourg N, Brenguier L, Devaud C, Pasturaud P, Roudaut C, et al. Mutations in the proteolytic enzyme calpain 3 cause limb-girdle muscular dystrophy type $2 \mathrm{~A}$ Cell 1995;81:27-40.

11 Bashir R, Britton S, Strachan T, Keers S, Vafiadaki E, Lako M, Richard I, Marchand S, Bourg N, Argov Z, Sadeh M, Mahineh I, Marconi G, PassosBueno MR, Moreira Ede S, Zatz M, Beckmann JS, Bushby K. A gene related to Caenorhabditis elegans spermatogenesis factor fer- 1 is mutated in limb-girdle muscular dystrophy type 2B. Nat Genet 1998;20:37-42.

12 Liu J, Aoki M, Illa I, Wu C, Fardeau M, Angelini C, Serrano C, Urtizberea JA, Hentati F, Hamida MB, Bohlega S, Culper EJ, Amato AA, Bossie K, Oeltien J, Bejaoui K, McKenna-Yasek D, Hosler BA, Schurr E, Arahata K, de Jong PJ, Brown RH. Dysferlin, a novel skeletal muscle gene, is mutated in Miyoshi myopathy and limb girdle muscular dystrophy. Nat Genet 1998;20:31-6.

13 Roberds SL, Leturcq F, Allamand V, Piccolo F, Jeanpierre M, Anderson RD, Lim LE, Lee JC, Tome FMS, Romero NB, et al. Missense mutations in the adhalin gene linked to autosomal recessive muscular dystrophy. Cell 1994;78:625-33.

14 Bonnemann CG, Modi R, Noguchi S, Mizuno Y, Yoshida M, Gussoni E, McNally EM, Duggan DJ, Angelini C, Hoffman EP. Beta-sarcoglycan (A3b) mutations cause autosomal recessive muscular dystrophy with loss of the sarcoglycan complex. Nat Genet 1995; 11:266-73.

15 Lim LE, Duclos F, Broux O, Bourg N, Sunada Y, Allamand V, Meyer J, Richard I, Moomaw C, Slaughter C, et al. Beta-sarcoglycan: characterization and role in limb-girdle muscular dystrophy linked to $4 q 12$. Nat Genet 1995; 11:257-65.

16 Noguchi S, McNally EM, Ben Othmane K, Hagiwara Y, Mizuno Y, Yoshida M, Yamamoto H, Bonnemann CG, Gussoni E, Denton PH, et al. Mutations in the dystrophin-associated protein gamma-sarcoglycan in chromosome 13 muscular dystrophy. Science 1995;270:819-22.

17 Nigro V, Moreira ES, Piluso G, Vainzof M, Belsito A, Politano L, Puca AA, Passos-Bueno MR, Zatz M. Autosomal recessive limb-girdle muscular dystrophy, LGMD2F, is caused by a mutation in the delta-sarcoglycan gene. Nat Genet 1996;14:195-8.

18 Nigro V, Piluso G, Belsito A, Politano L, Puca AA, Papparella S, Rossi E, Viglietto G, Esposito MG, Abbondanza C, Medici N, Molinari AM, Nigro G, Puca GA. Identification of a novel sarcoglycan gene at $5 q 33$ encoding a sarcolemmal 35 kDa glycoprotein. Hum Mol Genet 1996;5:1 179-86.

19 Moreira ES, Wiltshire TJ, Faulkner G, Nilforoushan A, Vainzof M, Suzuki OT, Valle G, Reeves R, Zatz M, Passos-Bueno MR, Jenne DE. Limb-girdle muscular dystrophy type $2 G$ is caused by mutations in the gene encoding the sarcomeric protein telethonin. Nat Genet 2000;24:163-6.

20 Frosk P, Weiler T, Nylen E, Sudha T, Greenberg CR, Morgan K, Fujiwara TM, Wrogemann K. Limb-girdle muscular dystrophy type $2 \mathrm{H}$ associated with mutation in TRIM32, a putative E3-ubiquitin-ligase gene. Am J Hum Genet 2002;70:663-72

21 Brockington M, Yuva Y, Prandini P, Brown SC, Torelli S, Benson MA, Herrmann R, Anderson LV, Bashir R, Burgunder JM, Fallet S, Romero N, Fardeau M, Straub V, Storey G, Pollitt C, Richard I, Sewry CA, Bushby K, Voit T, Blake DJ, Muntoni F. Mutations in the fukutin-related protein gene (FKRP) identify limb girdle muscular dystrophy 21 as a milder allelic variant of congenital muscular dystrophy MDC1C. Hum Mol Genet 2001;10:2851-9.

22 Hackman P, Vihola A, Haravuori H, Marchand S, Sarparanta J, De Seze J, Labeit S, Witt C, Peltonen L, Richard I, Udd B. Tibial muscular dystrophy is a titinopathy caused by mutations in TTN, the gene encoding the giant skeletalmuscle protein titin. Am J Hum Genet 2002;71:492-500.

23 Goll DE, Thompson VF, Li H, Wei W, Cong J. The calpain system. Physiol Rev 2003;83:731-801.

24 Carafoli E, Molinari M. Calpain: a protease in search of a function? Biochem Biophys Res Commun 1998;247:193-203.

25 Ono Y, Shimada H, Sorimachi H, Richard I, Saido TC, Beckmann JS, Ishiura S, Suzuki K. Functional defects of a muscle-specific calpain p94, caused by mutations associated with limb-girdle muscular dystrophy type 2A. J Biol Chem 1998;273:17073-8.

26 Baghdiguian S, Martin M, Richard I, Pons F, Astier C, Bourg N, Hay RT, Chemaly R, Halaby G, Loiselet J. Calpain 3 deficiency is associated with myonuclear apoptosis and profound perturbation of the lkappaB alpha/NF. kappaB pathway in limb-girdle muscular dystrophy type 2A. Nat Med 1999:5:503-11.

27 Kramerova I, Kudryashova E, Tidball JG, Spencer MJ. Null mutation of calpain 3 (p94) in mice causes abnormal sarcomere formation in vivo and in vitro. Hum Mol Genet 2004;13:1373-88.
28 Chae J, Minami N, Jin Y, Nakagawa M, Murayama K, Igarashi F, Nonaka I. Calpain 3 gene mutations: genetic and clinico-pathologic findings in limbgirdle muscular dystrophy. Neuromuscul Disord 2001;11:547-55.

29 Fanin M, Fulizio L, Nascimbeni AC, Spinazzi M, Piluso G, Ventriglia VM, Ruzza G, Siciliano G, Trevisan CP, Politano L, Nigro V, Angelini C. Molecular diagnosis in LGMD2A: mutation analysis or protein testing? Hum Mutat 2004;24:52-62.

30 Richard I, Bourg N, Marchand S, Alibert O, Eymard B, van der Kooi AJ, Jackson CE, Garcia C, Burgunder JM, Legum C, de Visser M, Fardeau M, Beckmann JS. A diagnostic fluorescent marker kit for six limb girdle muscular dystrophies. Neuromuscul Disord 1999;9:555-63.

31 Takashima H, Boerkoel CF, Lupski JR. Screening for mutations in a genetically heterogeneous disorder: DHPLC versus DNA sequence for mutation detection in multiple genes causing Charcot-Marie-Tooth neuropathy. Genet Med $2001 ; 3: 335-42$.

32 Sevilla C, Moatti JP, Julian-Reynier C, Eisinger F, Stoppa-Lyonnet D, Bressacde Paillerets B, Sobol $\mathrm{H}$. Testing for BRCA1 mutations: a cost-effectiveness analysis. Eur J Hum Genet 2002;10:599-606.

33 Bunn CF, Lintott CJ, Scott RS, George PM. Comparison of SSCP and DHPLC for the detection of LDLR mutations in a New Zealand cohort. Hum Mutat 2002; 19:311.

34 Eng C, Brody LC, Wagner TM, Devilee P, Vijg J, Szabo C, Tavtigian SV, Nathanson KL, Ostrander E, Frank TS, Steering Committee of the Breast Cancer Information Core (BIC) Consortium. Interpreting epidemiological research: blinded comparison of methods used to estimate the prevalence of inherited mutations in BRCA1. J Med Genet 2001;38:824-33.

35 Jones AC, Austin J, Hansen N, Hoogendoorn B, Oefner PJ, Cheadle JP, $\mathrm{O}^{\prime}$ Donovan MC. Optimal temperature selection for mutation detection by denaturing HPLC and comparison to single-stranded conformation polymorphism and heteroduplex analysis. Clin Chem 1999;45:1133-40.

36 Lacerra G, Fiorito M, Musollino G, Di Noce F, Esposito M, Nigro V, Gaudiano C, Carestia C. Sequence variations of the alpha-globin genes: scanning of high CG content genes with DHPLC and DG-DGGE. Hum Mutat 2004;24:338-49.

37 de Paula F, Vainzof M, Passos-Bueno MR de Cassia M Pavanello, R, Matioli SR, Anderson L, Nigro V, Zatz M. Clinical variability in calpainopathy: what makes the difference? Eur J Hum Genet 2002;10:825-32.

38 Jurkat-Rott K, Lehmann-Horn F. Periodic paralysis mutation MiRP2-R83H in controls: Interpretations and general recommendation. Neurology 2004;62:1012-15

39 Canki-Klain N, Milic A, Kovac B, Trlaja A, Grgicevic D, Zurak N, Fardeau M, Leturca F, Kaplan JC, Urtizberea JA, Politano L, Piluso G, Feingold J. Prevalence of the 550delA mutation in calpainopathy (LGMD 2A) in Croatia. Am J Med Genet 2004;125A:152-6.

40 Pogoda TV, Krakhmaleva IN, Lipatova NA, Shakhovskaya NI, Shishkin SS, Limborska SA. High incidence of 550delA mutation of CAPN3 in LGMD2 patients from Russia. Hum Mutat 2000;15:295

41 Groman JD, Hefferon TW, Casals T, Bassas L, Estivill X, Des Georges M, Guittard C, Koudova M, Fallin MD, Nemeth K, Fekete G, Kadasi L, Friedman K, Schwarz M, Bombieri C, Pignatti PF, Kanavakis E, Tzetis M Schwartz M, Novelli G, D'Apice MR, Sobczynska-Tomaszewska A, Bal J,, Stuhrmann M, Macek M, Claustres M, Cutting GR. Variation in a repeat sequence determines whether a common variant of the cystic fibrosis transmembrane conductance regulator gene is pathogenic or benign Am J Hum Genet 2004;74:176-9.

42 Chillon M, Casals T, Mercier B, Bassas L, Lissens W, Silber S, Romey MC, Ruiz-Romero J, Verlingue C, Claustres M. Mutations in the cystic fibrosis gene in patients with congenital absence of the vas deferens. N Engl J Med 1995;332: 1475-80.

43 Dryja TP, Berson EL. Retinitis pigmentosa and allied diseases. Implications of genetic heterogeneity. Invest Ophthalmol Vis Sci 1995:36:1197-200.

44 Rivolta C, Sharon D, DeAngelis MM, Dryja TP. Retinitis pigmentosa and allied diseases: numerous diseases, genes, and inheritance patterns. Hum Mol Genet 2002;11:1219-27.

45 Chelly J, Mandel JL. Monogenic causes of X-linked mental retardation. Nat Rev Genet $2001 ; 2: 669-80$.

46 Chiurazzi P, Hamel BC, Neri G. XLMR genes: update 2000. Eur J Hum Genet $2001 ; 9: 71-81$

47 Richard I, Roudaut C, Saenz A, Pogue R, Grimbergen JE, Anderson LV, Beley C, Cobo AM, de Diego C, Eymard B, Gallano P, Ginjaar HB, Lasa A, Pollitt C, Topaloglu H, Urtizberea JA, de Visser M, van der Kooi A, Bushby K, Bakker E, Lopez de Munain A, Fardeau M, Beckmann JS. Calpainopathy - a survey of mutations and polymorphisms. Am J Hum Genet 1999;64:1524-40. 